\title{
Asepsis and monitoring during US guided peripheral regional anaesthesia block at tertiary care hospital
}

Gurmukh Das Punshi, Siobhan Clarke, Karthikeyan Srinivasan, Patrick Conroy

Department of Anaesthesia,Tallaght University Hospital, Dublin

\section{Background \& Aim}

Ultrasound (US) has revolutionised many practices in anaesthesia and is being used with increasing frequency in the administration of neuraxial and peripheral nerve blocks. Although best practice guidelines have been published on the use of aseptic techniques and monitoring in invasive anaesthetic procedures ${ }^{1-3}$ their application is often inconsistent. We sought to evaluate the current practice surrounding US guided peripheral nerve blockade with a view to implementing systematic reform through defined aseptic guidelines.

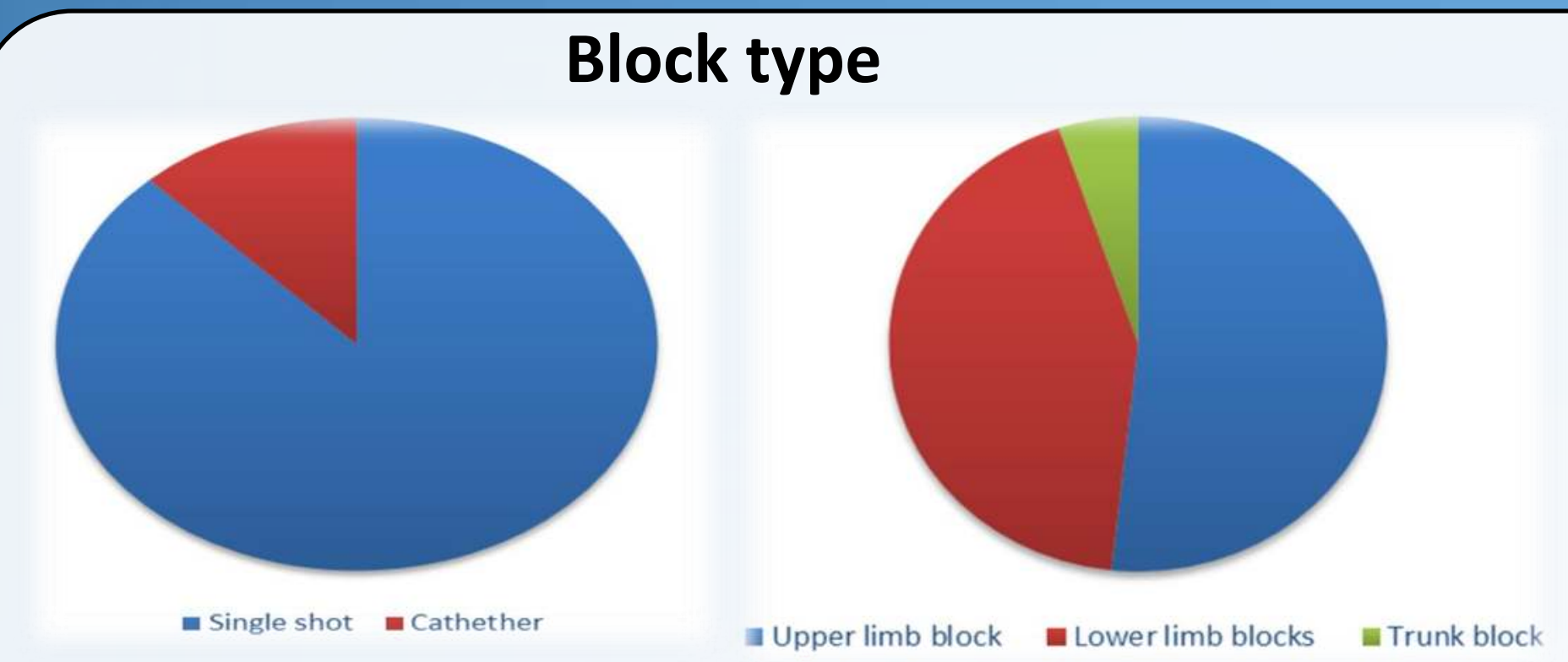

Indication and operator

\section{Results}
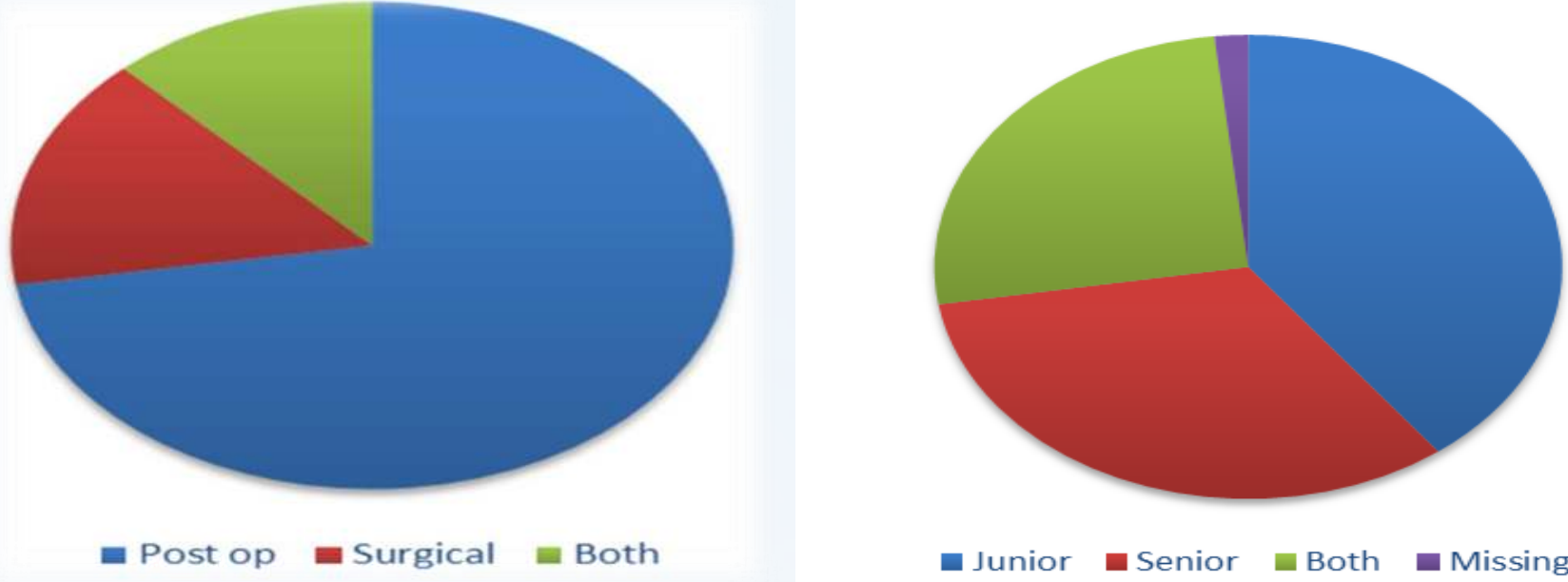

Of the 58 cases included in the study; Single shot (88\%), upper limb blocks (52\%) were carried out in the majority. 23 of the 58 cases were carried out by trainee anaesthetists under direct supervision, 19 by consultants and 15 cases involved both

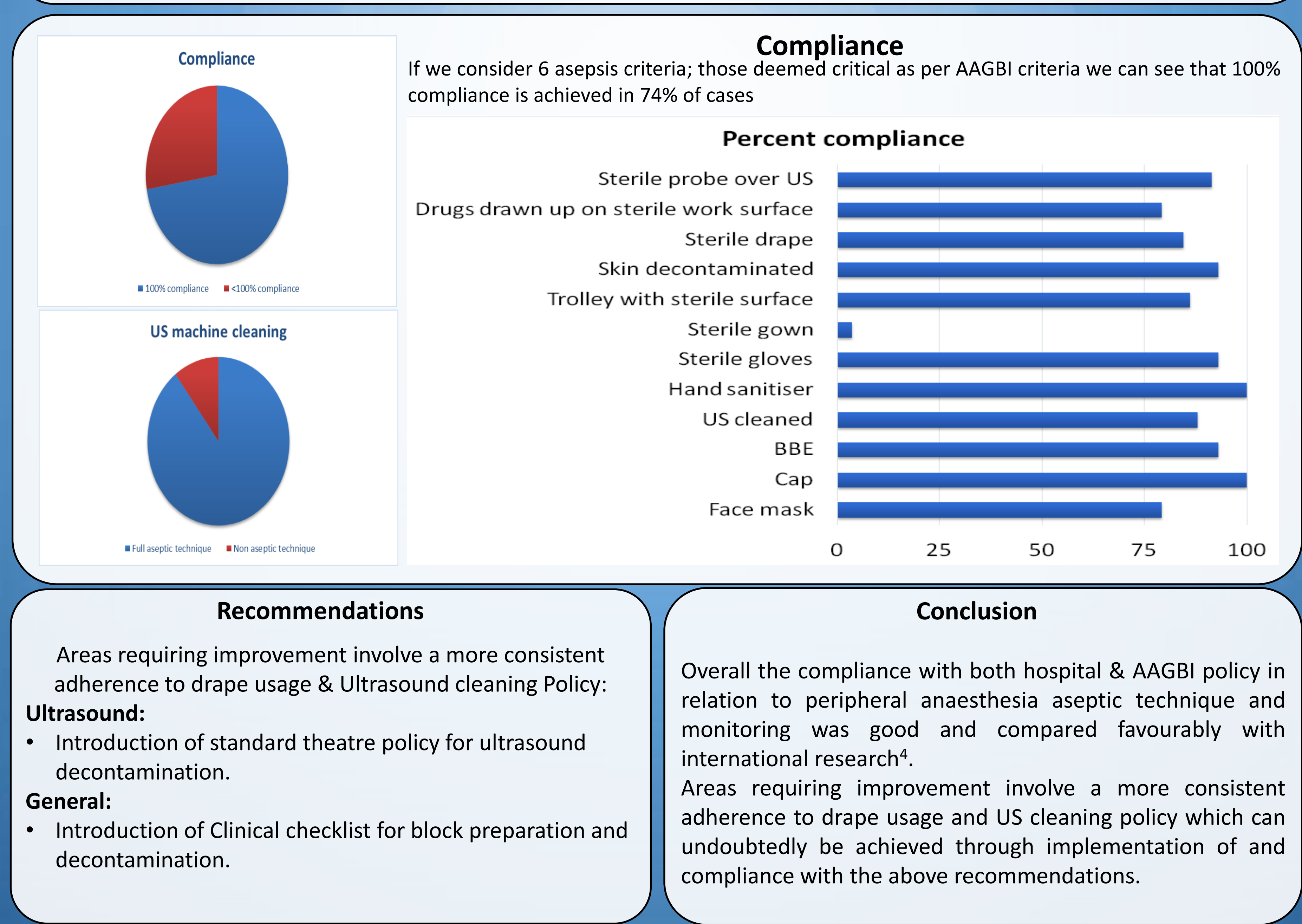

